\title{
Results of Coronary Artery Bypass Graft Surgery in Sharq Elmadina Hospital, Alexandria
}

\author{
El Husseiny E. Gamil ${ }^{1}$, Ali R. Mahmoud ${ }^{2}$, Mohamed E. Mahmoud ${ }^{1}$, Mohamed A. Mohamed \\ Departments of ${ }^{1}$ Cardiothoracic Surgery and ${ }^{2}$ General Surgery \\ Faculty of Medicine, Al-Azhar University \\ *Corresponding author: Mohamed A. Abd El Badie; Mobile: 01012972837, E-Mail: badi388@gmail.com
}

\begin{abstract}
Background: coronary artery bypass graft $(\mathrm{CABG})$ surgery has been shown to be an effective method for treating angina pectoris and prolonging life in patients with severe coronary artery disease.

Aim of the Work: to assess postoperative short-term results of coronary artery bypass graft surgery in Shark Elmedina hospital, Alexandria. Patients and Methods: This retrospective study was conducted on 170 patients with isolated ischemic heart disease admitted to Shark Elmadina hospital from January 2016 to January 2017. In the current study, pre-operative data were collected to identify the risk factors that may affect the outcome of surgery and intraoperative data and post-operative complications. Results: The most common risk factors were dyslipidemia (64.7\%), hypertension (57.1\%), diabetes mellitus which represents $50 \%$, smoking which represents $37,6 \%$, peripheral vascular disease which represents $31,7 \%$. Other risk factors which had a low percent were history of chronic hepatic disease, previous stroke or myocardial infarction or lung disease or renal disease. What is worth to mention that echo preoperative affects the outcome of surgery as in our study EF of patients' ranges from $40 \%$ to $75 \%$. Intraoperative data also affects the outcome of surgery as number of grafts as there was one patient had done 5 grafts and 34 patients have done 4 grafts. Another important event was LLIMA dissection as there were 9 patients have dissected LIMA during harvesting. Another event was endartrectomy as there were 11 patients have LAD endartrectomy, 6 patients have RCA endartrectomy. Long bypass time and clamp time affects the results of surgery maximum bypass time 200 minute and maximum clamp time 120 minute. Post-operative ICU and ward stay affects the results as maximum ICU or ward stay was 9 days. The most common complication was wound infection which had an incidence $7 \%$ and the second complication was renal impairment which had an incidence 5.2\%, reopening (2.9\%), elevated liver enzymes which represents 2,3\% and other complications which had low incidence as pleural effusion, lung atelectasis and stoke. Finally, mortality was $1.1 \%$. Conclusion: CABG surgery is safe and the risk of major complications is low. Although major complications occur rarely they pose a great challenge to the patient and the surgeon. Early recognition and management of major complications are paramount to long term outcome.
\end{abstract}

Keywords: coronary artery bypass graft surgery, postoperative short-term outcome.

\section{INTRODUCTION}

Coronary artery disease (CAD) is the leading cause of death globally, and is expected to account for $14.2 \%$ of all death by $2030^{(1)}$. According to the statistics from the American Heart Association (AHA), mortality data show that cardiovascular disease, as the underlying or accounted for $34.3 \%$ of all (1 of every 2.9) deaths $^{(2)}$.

Several alternative treatments exist for (CAD), including medical therapy, percutaneous coronary intervention (PCI) or balloon angioplasty, and coronary artery bypass graft surgery (CABG). Depending on the severity, number and position of atherosclerotic lesions and the clinical history of the patient, any of the abovementioned treatment may be chosen. For high- risk patients, such as those with left main coronary artery disease, severe three- coronary vessel disease, severe ventricular dysfunction (low ejection fraction $\mathrm{EF}$ ), and diabetes mellitus(DM), $\mathrm{CABG}$ is preferred treatment ${ }^{(3)}$.
CABG is a surgical procedure to use the own patient conduit to bypass the atherosclerotic narrowing and improve blood supply to the coronary circulation, for nourishing the myocardium ${ }^{(4)}$.

Myocardial revascularization has been an established mainstay in the treatment of coronary artery disease for almost half a century, used in clinical practice since 1960s. It is the most intensively studied surgical procedure ever undertaken ${ }^{(5)}$.

Despite the novel other alternatives for coronary artery revascularization, CABG is still one of the most durable and effective means of revascularization for patients with coronary heart disease either on pump or Off pump coronary artery bypass (OPCAB), using left internal mammary artery, right internal mammary artery, radial artery and saphenous venous grafts in addition to other grafts options ${ }^{(6)}$. Each year, 600,000 patients in USA undergo myocardial 
revascularization with cardiopulmonary bypass and sustain profound physiologic perturbations that precipitate ischemia and infarction in several organ systems. ${ }^{(7)}$ Although the conduct of CABG with cardiopulmonary bypass (CPB) has evolved with continual improvement in morbidity and mortality, cardiopulmonary bypass is known to induce a proinflammatory state with several adverse consequences $^{(8)}$. Clinically, the manifestations of cardiopulmonary bypass associated with morbidity include neurological dysfunction, ${ }^{(9)}$ pulmonary dysfunction, ${ }^{(10)}$ renal dysfunction, ${ }^{(11)}$ and possibly infectious-related complications ${ }^{(12)}$.

\section{AIM OF THE WORK}

The aim of this study is to assess postoperative short term results of coronary artery bypass graft surgery in Shark Elmedina hospital, Alexandria.

\section{PATIENTS AND METHODS Patients:}

This study was carried on 170 patients admitted to Shark Elmadina Hospital from January 2016 to January 2017 . The study was approved by the Ethics Board of Al-Azhar University. Inclusion Criteria: disease.

Patients with isolated ischemic heart

\section{Exclusion Criteria:}

Patients with compound heart disease, severe comorbidities, advanced old age.

Methods:

In the present study, the following data was retrospectively collected for the patients who had done CABG.

All patients in this study were subjected to the following:

\section{A. Preoperative assessment:}

1. History taking (age, sex, weight, history of chronic disease, surgical history, medical history).

2. General examination (heart, chest, abdomen, lower limbs, any neurological deficits).

3. Routine preoperative labs (complete blood count, bleeding profile, kidney function test, liver function test, urine analysis, viral markers).

1) Routine preoperative investigations; Chest $X$ ray: mediastinum, costophrenic angles, lung opacity or hypertransleucency, cardiothoracic ratio.

Electrocardiogram «ECG»: rhythm, rate, old ischemic changes.

Echocardiography: EF, dimensions, resting regional wall motionabnormality, any valvular lesions.

Coronary angiography: left main lesion, single vessel disease or multiple vessel disease. Lesions).

\section{B. Intra-operative data:}

All patients underwent CABG; the procedure was done under general anaesthesia in supine position. The following step is skin incision, mediansternotomy, harvesting of left internal mammary artery \& saphenous vein graft from the leg then opening of pericardium and aorto-venous cannulation then going on bypass, putting cross clamp on the aorta give cardioplegia, distal end anastomosis of the grafts on the heart, cross clamp off, starting rewarming, then putting $\mathrm{C}$ clamp on the aorta, grafting of proximal end of the grafts to the aorta; then removal of $\mathrm{C}$ clamp, starting reperfusion time according to the time of cross clamp then starting weaning from bypass, after smooth weaning off bypass aortovenosdecannulation, good haemostasis to suture lines, closure of chest wall in layers after putting chest tubes for drainage. The following data was collected:

1. Number of graft (single or multiple grafts).

2. Type of graft: single mammary versus double mammary and/or total venous graft (arterial, venous).

3. Operative time, bypass time, cross clamp time.

4. Number of dissected LIMA.

5. Vessels that have endartrectomy.

6. Probe that had used.

C. Postoperative assessment:

1. Data of ICU monitoring (pulse, invasive and non-invasive blood pressure, central venous pressures and urine output, balance.

2. ICU medications and need for inotropic support.

3. Postoperative complications:

- Postoperative Bleeding and blood transfusion.

- Postoperative myocardial Infarction and Low Cardiac Output manifestations.

- Postoperative Renal Dysfunction.

- Neurological Complications.

- Arrhythmias.

- Wound Infection.

- Mortality (early, intermediate, late).

- Post-operative laboratory follow up.

4. Hospital stay.

5. Early postoperative echocardiography before discharge from hospital.

6. Six month follow up by clinical examination, postoperative chest $\mathrm{X}$ ray, postoperative echocardiography, postoperative ECG.

Statistical analysis of the data:

Data were fed to the computer and analyzed using IBM SPSS software package 
version 20.0 (Armonk, NY: IBM Corp). Qualitative data were described using number and percent. The Kolmogorov-Smirnov test was used to verify the normality of distribution. Quantitative data were described using range (minimum and maximum), mean, standard deviation and median. Significance of the obtained results was judged at the $5 \%$ level ${ }^{(95)}$.

The used tests were

\section{1- Chi-square test:}

It was used for categorical variables, to compare between different groups.

\section{2- Fisher's Exact or Monte Carlo correction:}

Correction for chi-square when more than $20 \%$ of the cells have expected count less than 5 .

\section{3 - McNemar:}

It was used to analyze the significance between the different stages.

\section{4 - Student t-test:}

For normally distributed quantitative variables, to compare between two studied groups.

\section{5 - Paired t-test:}

For normally distributed quantitative variables, to compare between two periods.

\section{6- Mann Whitney test:}

For abnormally distributed quantitative variables, to compare between two studied groups.

\section{7 -Wilcoxon signed ranks test:}

For abnormally distributed quantitative variables, to compare between two periods ${ }^{(96)}$.

\section{RESULTS}

\section{Demographic data (Age, sex, weight):}

This study included 170 patients, one hundred twenty-seven (74.7\%) males and forty -three females $(25,3 \%)$. The minimum age recorded in this study was 45 years old and the maximum age was 70years old with a median age of (52.50) and mean $\pm \mathrm{SD}$ $(57.43 \pm 8.79)$. The minimum weight recorded in this study was $56 \mathrm{~kg}$ and the maximum weight was 155 $\mathrm{kg}$ with a median weight of (88.50) and Mean \pm SD $(89.68 \pm 16.28)$.

Table (1): Distribution of the studied cases according to age, sex and weight

\begin{tabular}{|l|c|c|}
\hline \hline & No. & \% \\
\hline \hline Sex & 127 & 74.7 \\
Male & 43 & 25.3 \\
Female & & \\
\hline Age (years) & $45.0-70.0$ \\
Min. - Max. & $57.43 \pm 8.79$ \\
Mean \pm SD. & 52.50 \\
Median & \\
Weight & $56.0-155.0$ \\
Min. - Max. & $89.68 \pm 16.28$ \\
Mean \pm SD. & 88.50 \\
Median & \\
\hline
\end{tabular}

\section{Past history}

The eighty-five $(50 \%)$ of patients were diabetic, ninety-seven (57\%) were hypertensive, eight patients $(4,7 \%)$ were hepatic, sixtyfour $(37,6 \%)$ were smoker, tow patients $(1 \%)$ had lung disease, ten $(5,9 \%)$ had renal stone, tow patients $(1 \%)$ were had stroke, sex patients $(3,5 \%)$ had myocardial infarction, one hundred and ten patients $(64,7 \%)$ had dyslipidemia, fifty four patients $(31,7 \%)$ had Peripheral vascular disease, twenty nine patients $(17 \%)$ had carotid artery disease, twenty five patients $(14,7 \%)$ had lower limb disease.

Table (2): Distribution of the studied cases according to past history

\begin{tabular}{|l|c|c|}
\hline \multicolumn{1}{|c|}{ Past history variables } & No. & \% \\
\hline \hline DM & 85 & 50.0 \\
HTN & 97 & 57.1 \\
Hepatitis c virus & 8 & 4.7 \\
Smoker & 64 & 37.6 \\
Lung disease & 2 & 1.2 \\
Renal disease & 10 & 5.9 \\
Stroke & 2 & 1.2 \\
MI & 6 & 3.5 \\
Dyslipidemia & 110 & 64.7 \\
Peripheral vascular disease & 54 & 31.7 \\
carotid artery disease & 29 & 17 \\
ll disease & 25 & 14.7 \\
\hline \hline
\end{tabular}

\section{Pre-operative echo}

In our study there were minimum EF recorded (40\%), maximum EF recorded (75\%), median EF recorded $(60 \%)$, Mean $\pm \mathrm{SD}(58.92 \pm 8.98)$. Minimum end systolic diameter $(2,6 \mathrm{~cm})$, maximum $(6$, $1 \mathrm{~cm})$, Mean $\pm \mathrm{SD}(3.4 \pm 0.84)$, median (3.6 $\mathrm{cm})$. Minimum end diastolic diameter $(3 \mathrm{~cm})$, Maximum $(8,2 \mathrm{~cm})$, Mean $\pm \mathrm{SD}(4.8 \pm 1.07)$, median $(5,05 \mathrm{~cm})$. Minimum left atrial diameter $(2,6 \mathrm{~cm})$, maximum $(4,9 \mathrm{~cm})$, Mean $\pm \mathrm{SD}(3.4 \pm 0.6)$, median $(3,7 \mathrm{~cm})$. 
Table (3): Descriptive analysis of the studied cases according to Pre-operative echo

\begin{tabular}{||l|c|c|c||}
\hline & Min. - Max. & Mean \pm SD. & Median \\
\hline \hline EF & $40.0-75.0$ & $58.92 \pm 8.98$ & 60.0 \\
\hline ES & $2.5-6.1$ & $3.4 \pm 0.84$ & 3.6 \\
\hline ED & $3-8.2$ & $4.8 \pm 1.07$ & 5.05 \\
\hline LA & $2.6-4.9$ & $3.4 \pm 0.6$ & 3.7 \\
\hline
\end{tabular}

In our study there were fourty seven patients $(27,6 \%)$ had mild mitral regurge, thirty tow patients $(18,8 \%)$ had diastolic dysfunction, seventy tow patients $(42,4 \%)$ had Resting regional wall motion abnormalities.

Table (4): Descriptive analysis of the studied cases according to another data of Pre-operative echo.

\begin{tabular}{|l|c|c||}
\hline & No. & \% \\
\hline \hline Mild mitral regurge & 47 & 27.6 \\
Diastolic dysfunction & 32 & 18.8 \\
Resting regional wall motion abnormalities & 72 & 42.4 \\
\hline
\end{tabular}

\section{Pre-operative coronary angiography}

In our study there were twenty-three patients $(13,5 \%)$ had left main disease, eighteen patients $(10,6)$ had single vessel disease one hundred twenty-nine( 75,9$)$ had multivessele disease.

Table (5): Descriptive analysis of the studied cases according to Pre-operative coronary angiography.

\begin{tabular}{|l|c|c||}
\hline & No. & \% \\
\hline \hline & & \\
Left Maia lesion & 23 & 13.5 \\
Single vessel diseases & 18 & 10.6 \\
Multiple vessel diseases & 129 & 75.9 \\
\hline
\end{tabular}

\section{Dissected LIMA \& end artrectomy}

In our study there were nine patients $(5,29 \%)$ had dissected LIMA, eleven patients $(6,4 \%)$ had LADendartrectomy, six patients $(3,5 \%)$ had RCA endartrectomy

Table (6): Descriptive analysis of the studied cases according to dissected LIMA \& end artrectomy.

\begin{tabular}{|l|c|c||}
\hline & No. & \% \\
\hline \hline Number of dissectedLIMA & 9 & 5.29 \\
Number f LAD which had endartrectomy & 11 & 6.4 \\
Number of RCA which had endartrectomy & 6 & 3.5 \\
\hline
\end{tabular}

\section{Probe used with LAD}

In our study there were only one hundred and thirty patients $(76,4 \%)$ thatthat had LAD which had passedprobe $1,5 \mathrm{~cm}$, fourty patients $(23,5 \%)$ thatthat had LAD which had passedprobe $1 \mathrm{~cm}$.

Table (7): Descriptive analysis of the studied cases according to probe used with LAD

\begin{tabular}{|l|c|c|}
\hline & No. & \% \\
\hline Number of LAD that had passed probe 1,5mm & 130 & 76,4 \\
Number of LAD that had passed probe 1mm & 40 & 23,5 \\
\hline \hline
\end{tabular}

\section{Number of grafts}

In our study there weretwenty-five patients $(14,7 \%)$ had single graft,fourty-six patients $(27 \%)$ had two grafts, sixty-four patients $(37,6 \%)$ had three grafts, thirty-four patients(20\%) had four grafts, one patient (1\%) had five graft. 
Table (8): Distribution of the studied cases according to number of grafts .

\begin{tabular}{|c|c|c|}
\hline & No. & $\%$ \\
\hline $\begin{array}{c}\text { Number of grafts } \\
1 \\
2 \\
3 \\
4 \\
5\end{array}$ & $\begin{array}{c}25 \\
46 \\
64 \\
34 \\
1\end{array}$ & $\begin{array}{c}14.7 \\
27.1 \\
37.6 \\
20.0 \\
0.6\end{array}$ \\
\hline $\begin{array}{l}\text { Min. - Max. } \\
\text { Mean } \pm \text { SD. } \\
\text { Median }\end{array}$ & \multicolumn{2}{|c|}{$\begin{array}{c}1.0-5.0 \\
2.65 \pm 0.98 \\
3.03\end{array}$} \\
\hline
\end{tabular}

\section{Bypass time \& cross clamp time}

According to results, the bypass time of the studied cases were between (40 mint) and (200 mint) with a Mean \pm SD $(80.79 \pm 38.50)$ and median(80), but cross clamp time of the studied cases were between (20 mint) and (120 mint) with a Mean \pm SD (38.65 \pm 18.87$)$ and median(35)

Table (9): Descriptive analysis of the studied cases according bypass time \& cross clamp time

\begin{tabular}{|l|c|c|c|}
\hline & Min. - Max. & Mean \pm SD. & Median \\
\hline \hline Bypass time (min.) & $40.0-200.0$ & $80.79 \pm 38.50$ & 80.0 \\
Clamp time (min.) & $20.0-120.0$ & $38.65 \pm 18.87$ & 35.0 \\
\hline \hline
\end{tabular}

\section{Inotropes \& in zero \& first day}

In our study the recorded patients that had received inotrpes were one hundred and three (60,6\%)in zero day \&fifty three $(31,17 \%)$ in first day but in contralateral side there weresexty-seven $(39,4 \%)$ in zero day \&one hundred fourty-three $(84 \%)$ not received inotropes.

Table (10): Distribution of the studied cases according to inotropes in zero \& first day

\begin{tabular}{||l|c|c|c|c||}
\hline \multirow{2}{*}{} & \multicolumn{2}{|c|}{ Zero day } & \multicolumn{2}{c||}{$\mathbf{1}^{\text {st }}$ day } \\
\cline { 2 - 5 } & No. & \% & No. & \% \\
\hline \hline Ionotropes & & & & \\
No & 67 & 39.4 & 143 & 84.1 \\
Yes & 103 & 60.6 & 53 & 31.17 \\
\hline
\end{tabular}

\section{ICU stay \& ward stay}

In our study we recorded that staying of patients in ICU between two days(2) and nine days (9) with mean $\pm \operatorname{SD}(6,94 \pm 3,18)$ and median tow (2). But stauing inthe ward was between one day(2) and nine days (9) with mean $\pm \operatorname{SD}(6,94 \pm 3,11)$ and median tow (2) .

\section{Ejection fraction postoperative}

In our stydy there were minimum ejection fraction (25\%), maximum(70\%), Mean $\pm \operatorname{SD}(8,51 \pm 51.30)$, median $(50 \%)$.

Table (11): Descriptive analysis of the studied cases according to Ejection fraction postoperative

\begin{tabular}{|l|c|c||}
\hline \multicolumn{1}{|c|}{ EF Post-operative } & No. & $\%$ \\
\hline \hline$<50$ & 48 & 42.1 \\
$50-60$ & 53 & 46.5 \\
$>60-70$ & 12 & 10.5 \\
\hline Min. - Max. & \multicolumn{2}{|c||}{$25.0-70.0$} \\
Mean \pm SD. & \multicolumn{2}{|c|}{$51.30 \pm 8.51$} \\
Median & \multicolumn{2}{|c|}{50.0} \\
\hline
\end{tabular}

\section{Postoperative complications:}

\section{Immediate: $\mathrm{IAB}$}


- The present study revealed that one patient $(0,5 \%)$ required IAB, and this done early intra-operative after 3 grafts was done (LIMA-LAD, SVG-D, SVG-distal RCA ). Due to distention of the heart after weaning from $\mathrm{CPB}, \mathrm{SVG}$ anastomosis was done to LAD but we could not wean from bypass so finally this problem has been resolved by IAB . IAB was connected for 2 days in ICU and then was separated.

2. Early: ICU (renal impairment, elevated liver enzymes, reopening, chestinfection, atrial fibrillation, lung atelectasis, heart failure, stroke, mortality) WARD (wound infection, lt pleural chylothorax)

- In the current study, we found that there were 8 patients had superficial wound infection, according to culture \& sensitivity antibiotics was taken and frequent dressing was done and there were good results. Another 4 patients had deep sternal wound infection and vacuum dressing was done after good debridement and antibiotics according to culture and sensitivity was taken and there were good results.

4. Late: It pleural effusion

Table (13): Descriptive analysis of studied cases according to postoperative complications

\begin{tabular}{|c|c|c|}
\hline Number of cases & Percentage \% & Complications \\
\hline \hline 129 & $75,8 \%$ & unrecorded complications \\
\hline 12 & $7 \%$ & wound infecting \\
\hline 9 & $5,2 \%$ & renal impairment \\
\hline 4 & $2,3 \%$ & Elevated liver enzyme \\
\hline 5 & $2,9 \%$ & Reopening \\
\hline 3 & $1,7 \%$ & chest infection \\
\hline 3 & $1,7 \%$ & Lt Pleural effusion \\
\hline 2 & $1,1 \%$ & Atrial fibrillation \\
\hline 2 & $1,1 \%$ & lung atelectasis \\
\hline 1 & $0,5 \%$ & Lt Pleural chylothorax \\
\hline 1 & $0,5 \%$ & IAB \\
\hline 1 & $0,5 \%$ & Heart failure \\
\hline 1 & $0,5 \%$ & Stroke \\
\hline 2 & $1,1 \%$ & Mortality \\
\hline
\end{tabular}

\section{DISCUSSION}

Age is a significant risk factor for poor outcome after cardiac procedures and is included in all risk stratification scores. In our study, wefound thatthe minimum age recorded was (45) years old and the maximum age was (70) years old with a median age of (52.50) and mean \pm SD (57.43 \pm 8.79). Arif et al in 2016 found that mean age was $(82.4 \pm 2.3)$ years old ${ }^{(13)}$.

Sex is one of risk factors and in the present study, we found that $127(74,7 \%)$ patients were males and $43(25,3 \%)$ patients were females. Nashef et al. found that male sex was 264(68\%) patients and females was 124(31, 9\%) patients of total 388patients ${ }^{(\mathbf{1 4})}$.

Weight is one of the most important risk factors and in the current study, wefound that the minimum weight recorded was $56 \mathrm{~kg}$ and the maximum weight was $155 \mathrm{~kg}$ with a median weight of (88.50) and Mean \pm SD (89.68 \pm 16.28$)$. Nashef et al. found that normal weight were $119(30,7 \%)$ patients, underweight were $5(1,3 \%)$ patients, over weight were $179(46,1 \%)$ of total 388 patients ${ }^{(\mathbf{1 4})}$.

DM is one of the most important risk factor and in the present study, we found that diabetic patients were $85(50 \%)$ patients. Weisel $\boldsymbol{e t}$ al. in
2014 found that there were $127(32,7 \%)$ diabetic patients of total 388 patients ${ }^{(\mathbf{1 5})}$.

Hypertension is one of the most important risk factors and in the present study, We found that there were $97(57,1 \%)$ hypertensive patients. Nashef et al reported that there were 333(85, 8\%) hypertensive patients of total 388Patients ${ }^{(\mathbf{1 4})}$.

Hepatitis cvirus is one of risk factors pre CABG \& in the present study, We found that there were $8(4,7 \%)$ patients. Klemperer et al. found that total $26(0,5 \%)$ patients out of 4952 patients with liver cirrhosis were identifiedand etiologies of liver cirrhosis were predominantly infective hepatitis (hepatitis $\mathrm{c} n=13$ \&hepatitis $b \mathrm{n}=5$ and alcohol inducedn=8) ${ }^{(\mathbf{1 6})}$.

Smoking is one of the most important risk factors and in the present study, we found that there were $64(37,6 \%)$ patients were heavy smokers. Weisz et al. (17) in 2005found that all2587 consecutive patients underwent isolated CABG between February 2000 and June 2007. Of these $475(18,3 \%)$ patients were current smokers.

Preoperative lung disease is another important risk factors and in the present study, we found that there were $2(1,2 \%)$.These 2 patients were suffering from bronchial asthma. Weisel et al 
El Husseiny Gamil et al.

(15) found that there were $23(5,7 \%)$ patientshad chronic lung disease off total 388 patients.

Kidney disease before $\mathrm{CABG}$ is one of most important risk factors and in the present study, there were $5(5,9 \%)$ patients had renal disease as renal stone. A similar result was reported by Weisel et al. in 2014. They found that were 10 patients (5.9\%) had kidney disease ${ }^{(15)}$.

As regards stroke we found that there were 2 (1.2\%) patients had history of stroke. F LloydJones et al. found that there were $29(9,3 \%)$ patients had history of stroke pre-operatively ${ }^{(2)}$.

Myocardial infarction is an important risk factor pre-operatively and we found that there were $6(3,5 \%)$ patients had history of MI. Estafanous et al. found that there were 246 patients $(63,4 \%)$ had previous MI ${ }^{(18)}$.

Dyslipidemia is an important risk factor preoperatively and we foundthat there were 110 $(64,7 \%)$ patients had history of dyslipidemia. Previous studies ${ }^{(\mathbf{1 8 , 1 9 )}}$ found that there were 54 (13, 9\%) patients had history of hyperlipidemia.

Peripheral vascular disease is an important risk preoperatively as carotid artery stenosis or varicose veins or varicosities at lower limbs and in the present study, we found that there 54(31.7\%) patients had history of Peripheral vascular disease. Smetana et al. Leonard et al. ${ }^{(19,20)}$ found that there were $22(7.1 \%)$ patientshadperipheral vascular disease.

Preoperative echo is a very important investigation pre-operatively and my results in this study as compared with other studies there were: Douglas et $\boldsymbol{a l} .{ }^{(21)}$ of total number 667 patients recorded that:

- $\mathrm{EF}<30 \% \ldots 38$ patients $(5,7 \%)$

- $30-49 \%$...149 patients $(5,7 \%)$

- $50-69 \% \ldots . . .427$ patients $(64 \%)$

- $>70 \%$........53 patients $(8 \%)$

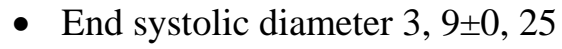

- End diastolic diameter 5, 3 $\pm 1,83$

- Left atrial dimensions $3,8 \pm 0,6$

- Diastolic dysfunction 225 patients $(33,7 \%)$

- Ischemic mitral regurge ..... trivial 392 patients $(58,8 \%)$, mild 222 patients $(33,3 \%)$

- Regional wall motion abnormality 310 patients $(31,6 \%)^{(21)}$

Coronary angiography preoperative is the most important pre-operative investigation and we found in the present study, there were $23(13,5 \%)$ patientshad left main disease, $18(10,6 \%)$ patientshad single vessel disease, $129(75,9 \%)$ patients had multivessele disease. Estafanous et al. in 2006found that LM disease 179(62,6\%) patients, single vessel disease $72(18,6 \%)$ patients, two vessel disease $69(17,8 \%)$ patients, three vessel disease 243(62,6\%)patientsoftotal 388 patients. ${ }^{(\mathbf{1 8})}$ Wound infection:

Despite efforts to reduce the incidence of surgical site infections, they remain a significant source of postoperative morbidity. Among 170 coronary bypass procedures performed there were 12 total SSIs for an overall incidence of $7 \%$. Vida Vet al in 2003 found that among 4004 coronary bypass procedures performed between January 1996 and May 2003, there were 160 total surgical site infections SSIs for an overall incidence of $4.0 \%$. ${ }^{(22)}$.

\section{Renal impairment}

Renal impairment is a potential complication of CABG that can arise from a variety of causes including preoperative, intraoperative, and postoperative. Among 170 coronary bypass procedures performed there were 9 casesdeveloped renal impairment (presented by elevated kidney function \& oliguria) with an overall incidence of $5 \%$. While some studies said that the incidence of acute renal failure described by Andersson et al ${ }^{(23)}$ was (16.4\%) and Zanardo et al. ${ }^{(24)}$ (15.1\%).

\section{Elevated liver enzyme:}

Despite demonstrable advances in all aspects of operative and perioperative management over the last decade, early jaundice and transient liver damage after modern extracorporeal circulation surgery is still occurs frequently ${ }^{(25)}$.Among 170 coronary bypass procedures performed there were 4 cases total for an overall incidence of 2, $4 \%$. Leal-Noval $\boldsymbol{e t}$ al. in $2011 \mathrm{had}$ found thatit has long been recognized that early jaundice and transient liver damage could occur after extracorporeal circulation surgery ${ }^{(26)}$.

\section{Reopening:}

When excessive mediastinal bleeding occurs, regardless the cause,re-sternotomy and exploration is highly indicated. Early exploration for persistent bleeding may reduce the requirement for homologous transfusions, risk of respiratory insufficiency and infection. ${ }^{(134)}$ Among 170 coronary bypass procedures performed there were 4 cases total for an overall incidence of 2, 4\%. Mastoraki et al. found that Overall, of the 2,898 patients in the study, 89 (3.1\% patients required re-exploration for bleeding after isolated CABG). Of the 89 patients re-explored, the primary indication for re-exploration was bleeding ( $\mathrm{n}$ $=75$ ) other indications included 10 cases of tamponade, 2 cardiac arrests with bleeding, and 2 others. The major sites of bleeding were as follows: 42 graft/anastomoses, 23 sternal/left internal mammary artery bed, 6 extra-pericardial, 2 cannulation sites, and 16 unspecified $^{(25)}$.

Chest infection: 
Results of Coronary Artery Bypass Graft Surgery...

Chest infection following cardiac coronary artery bypass graft surgery is often associated with significant morbidity and mortality. Among 170 coronary bypass procedures performed 3 cases developed chest infection with an overall incidence of $1,7 \%$. In about $50-70 \%$ of cases the responsible organisms are gram negative bacilli.The most important causative gram negative organisms include Klebsiella species, Escherichia coli and Pseudomonas Aeruginoza $^{(26)}$. Prolonged postoperative intubation and mechanical ventilation may lead to VAP, as can reintubation for reoperation, respiratory insufficiency, or cardiac failure. VAP has an incidence of $9 \%$ to $21 \%$ among patients with respiratory failure ${ }^{(27)}$.

\section{Pleural effusion:}

Pleural effusion is a common occurrence following heart surgery, but in most cases the fluid collection is small and not clinically significant. Some patients however, develop a significant effusion during the initial hospitalization or after hospital discharge, which requires drainage to relieve respiratory symptoms. Among 170 coronary bypass procedures performed there were 3 cases total for an overall incidence of 1,7\%. Myers et al. ${ }^{(28)}$ said that the overall incidence of symptomatic pleural effusion in the study was $9.8 \%$ (45 of 460), approximately twothirds of the effusions occurred during the initial hospitalizationbut another one-third occurred after hospital discharge ${ }^{(28)}$.

\section{Atrial fibrillation:}

Arrhythmias are common phenomenon after CABG. Among 170 coronary bypass procedures performed there were 3 cases total for an overall incidence of $1,7 \%$. Pires et al. ${ }^{(29)}$ found thatAF is usually of benign nature and is said to occur in about $25 \%$ of patients postoperatively after CABG.They found that postoperative causes of arrhythmias include ongoing myocardial ischemia, hypoxia, infections (e.g., pneumonia, wound infection), pericardial Collections / tamponade, electrolyte disturbances, coronary spasm, hypervolemia, pulmonary artery catheter irritation, and drug withdrawal/toxicity (e.g., beta-blockers, digoxin, and alcohol). ${ }^{(29)}$

\section{Lung atelectasis:}

Atelectasis is the most common postoperative complication which emerges more in patients with pulmonary and underlying diseases than other patients. Among 170 coronary bypass procedures performed there were 2 casesthat developed atelectasis with an overall incidence of $1,1 \%$. The most frequently observed radiologic abnormality was left lower-lobe atelectasis. It occurred in $73 \%$ of patients after internal mammary artery grafting and in 54\% when only vein grafts were used ${ }^{(30)}$.

Lt pleural chylothorax:
Chylothorax is the result of leakage from the thoracic duct or one of its main tributaries, is a rare complication of CABG. Among 170 coronary bypass procedures performed there was one reported case for an overall incidence of $0,5 \%$. Asimilar result was shown by Cevese et al. ${ }^{(31)}$ in 2001said thatchylothorax is a recognized complication of intrathoracic surgery, with an incidence of $0.25 \%$ to $0.5 \%$.

\section{Intra-aortic balloon pump:}

IABP is the most usable tool of temporary mechanical circulatory support for cardiac surgical patients suffered from low cardiac output in the early postoperative phase.Among 170 coronary bypass procedures performedone patient $(0,5 \%)$ required IAB. Other study as Christenson et al in 2010found that twenty-four patients (17.6\%) needed intra-aortic balloon inserted due to low Cardiac output syndrome. The incidence of patients needed IABP support per year was between 4.2 and $5 \%$ with a mean incidence of 4.3 $\pm 0,6^{(32)}$. The need for increased use of IABP during cardiac surgery in the recent years has been reported by many groups. This is mainly due to the fact that the patient population has changed and now includes older patients with multi-vessel disease and more impaired ventricles. On the other hand, there is a lower threshold for IABP use due to improve technology and lower rate of complications.

\section{Heart failure:}

Heart failure is a highly prevalent syndrome with a poor prognosis, resulting in substantial morbidity and reduced quality of life despite recent advances in treatment. Among 170 coronary bypass procedures performed one patient $(0,5 \%)$ developed heart failure which is a complex clinical syndrome that results from any structural or functional impairment of ventricular filling or ejection of blood. In most cases, acute HF arises because of deterioration in patients with previous diagnosis of HF (either HF-reduced EF or HF-preserved EF). Acute HF may occur in patients before (e.g., because of preoperative infarction), during (failure to wean), and after (mechanical complications and pericardial tamponade must be excluded). The durability of CABG results has increased with theuse of arterial grafts and ischemia stems mainly from saphenous vein graft $\mathrm{SVG}^{(33)}$.

\section{Stroke:}

Stroke is defined as any focal or global neurological deficit lasting for $>24 \mathrm{~h}$. Among 170 coronary bypass procedures performed, one case developed stroke. Ricotta et al. ${ }^{(34)}$ reported that Perioperative stroke is rare and affects 1-2\% of patients undergoing CABG surgery.

Mortality: 
El Husseiny Gamil et al.

Among 170 coronary bypass procedures performed, two $(1,1 \%)$ mortality caseswere reported . In the present study, we found that one patient died at zero day and another patient died at first day and the cause of death in both patients was myocardial ischemia as they had very bad targets. Adelborg et al. (35) in 2009 found that at 30 days, the mortality rate was $3.2 \%$ for patients who underwent isolated $\mathrm{CABG}$ surgery, causes of death showed that CABG patients had died from myocardial infarction, heart failure, or stroke.

\section{CONCLUSION}

CABG surgery has become increasingly safe and the risk of major complications is low. Although major complications occur rarely they pose a great challenge to the patient and the surgeon. Early recognition and management of major complications are paramount to long term outcome.

\section{REFERENCES}

1. Molina JA and Heng BH (2009): Global trends in cardiology and cardiothoracic surgery-an opportunity or threat? Ann Acad Med Singapore, 38:541-545.

2. Lloyd-Jones D, Adams RJ, Brown TM, Carnethon M, Dai S, De Simone F et al. (2010): Executive summary of heart disease and stroke statistics-2010 update: a report from the American heart association. Circulation, 121:e46-e215.

3. Rihl CS, Raco DL, Gersh BJ, Yusufs TB (2003): Indications for coronary artery bypass surgery and percutaneous coronary intervention in chronic stable angina:review of the evidence and methodological considerations. Circulations, 1039-1045.

4. De Bruyne B, Eeckhout E (1997): Ischemic Heart Disease: A Textbook of Cardiovascular Medicine. Philadelphia, PA: Saunders: Pp. 218-233.

5. Kolh P, Wijns W, Danchin N, Di Mario C, Falk VM, Folliguet $T$ (2010): The task force on myocardial revascularization of the European Society of Cardiology and the European Association for Cardiothoracic Surgery. Eur J Cardiothoracic Surg., 38: S1-52.

6. Swanson SJ, Sabiston DC, Spencer FC (2005): Surgical treatment of coronary artery disease. In: Sellke FW, del Nido PJ (eds), Sabiston and Spencer cardiothoracic surgery.7thed. Philadelphia: Elsevier Saunders, 37: 171-185.

7. Gibbon JH Jr (1954): Application of a mechanical heart and lung apparatus to cardiac surgery. Minn Med., 37: 171-185.

8. Garrett HE, Dennid EW, DeBakey ME (1973): Aorto-coronary bypass with saphenous vein graft: seven year follow-up. JAMA., 223: 792-794.

9. Almassi GH, Sommers T, Moritz TE, Shroyer AL, London MJ, Henderson WG (1999): Stroke in cardiac surgical patients: determinants and outcome. The annals of thoracic surgery, 68(2):391-7.
10. Asimakopoulos G, Smith PL, Ratnatunga CP, Taylor KM (1999): Lung injury and acute respiratory distress syndrome after cardiopulmonary bypass. The Annals of thoracic surgery, 68(3):1107-15.

11. Ascione R, Lloyd CT, Underwood MJ, Gomes WJ, Angelini GD (1999): On-pump versus off-pump coronary revascularization: evaluation of renal function. The Annals of thoracic surgery, 68(2):493-8.

12.Jensen RH, Storgaard M, Vedelsdal R, Obel N (1995): Impaired neutrophil chemotaxis after cardiac surgery, 29(3):55-68.

13. Arif R, Farag M, Gertner V, Szabó G, Weymann A, Veres G (2016): Female gender and differences in outcome after isolated coronary artery bypass graft surgery: does age play a role? PLoS One, 11(2):123126.

14. Nashef SA, Roques F, Michel P, Gauducheau E, Lemeshow S, Salamon R (1999): European system for cardiac operative risk evaluation (Euro SCORE). European journal of cardio-thoracic surgery,16(1):913.

15. Weisel R, Nussmeier N, Newman $M$, Pearl R, Wechsler A, Ambrosio G (2014): Predictors of coronary artery bypass grafting outcomes. Journal of Thoracic and Cardiovascular Surgery, 148(6):27-61.

16. Klemperer JD, KO W, Krieger KH, Connolly M, Rosengart TK, Altoki NK (1988): Cardiac operations in patients with cirrhosis .Ann Thorac surg., 65 :85-87.

17. Weisz G, Cox DA, Garcia E et al. (2005): Impact of smoking status on outcomes of primary coronary intervention for acute myocardial infarction, American Heart Journal, 150:58-64.

18. Estafanous F, Blum J, Loop F, Beck G, Paranandi L (2006): Stratification of morbidity and mortality outcome by preoperative risk factors in coronary artery bypass patients. A clinical severity score. Journal of the American Medical Association, 267(17): 44-48.

19. Smetana GW, Lawrence VA, Cornell JE(2009): Preoperative risk stratification for cardiothoracic surgery: systematic review for the American College of Physicians. Annals of Internal Medicine, 144(8):581595.

20.Leonard N, Biancari F, Horan PG, Herity NA (2006): Progressively increasing operative risk among patients referred for coronary artery bypass surgery. Ulster Med J., 75:136-140.

21.Douglas PS, Garcia MJ, Haines DE, Lai WW, Manning WJ, Patel AR, Picard MH, Polk DM, Ragosta M, Parker Ward R, Weiner RB (2011): Appropriate use criteria for echocardiography. J Am SocEchocardiogr., 24:229-267.

22. Gorcsan J, Diana P, Lee J, Katz WE, Hattler BG (1994): Reversible diastolic dysfunction after successful coronary artery bypass surgery. Assessment by transesophageal Doppler echocardiography. Chest, 106: 1364-9.

23. Andersson LG, Ekroth R, Bratteby LE, Hallhagen S, Wesslen $O$ (1993): Acute renal failure after coronary surgery--a study of incidence and risk factors in 2009 consecutive patients. ThoracCardiovasc Surg., 41(4):237-41. 
Results of Coronary Artery Bypass Graft Surgery...

24.Zanardo G, Michielon P, Paccagnella A, Rosi P, Calo M, Salandin Vet al. (1994): Acute renal failure in the patient undergoing cardiac operation. Prevalence, mortality rate, and main risk factors. J ThoracCardiovascSurg., 107(6):1489-95.

25. Mastoraki A, karatzis E, Mastoraki S, kriarasI, Sfirakis S, geroulanos S (2007): Postoperative jaundice after cardiac surgery. Jaundice J., 6:83-97.

26. Leal-Noval SR, Rincon-Ferrari MD, GarciaCurielA.liver affection post cardiopulmonary bypass. Thorac Cardiovasc Surg., 9:61-68.

27. Kollef MH, Sharpless L, Vlasnik J (1997): The impact of nosocomial infections on patient outcomes following cardiac surgery. Chest, 112:66-76.

28. Myers ML, Hurlbut D, Lefcoe M, Goldbach M (1998): Pleuropulmonary morbidity: internal thoracic artery versus saphenous vein grafts. The Annals of thoracic surgery, 50:59-64.

29. Pires LA, Chikwe, Wagshal AB, Lancey R, Kleinet, Huang $S$ (1996): Arrhythmias and conduction disturbances after coronaryartery bypass graft surgery: epidemiology, management, and prognosis. Am Heart J., 129(4):799-808.
30.Jain V, Rao TL, Kumar P, Kleinman BS (1996): Radiographic pulmonary abnormalities after different types of cardiac surgery. Journal of cardiothoracic and vascular anesthesia, 5:92-95.

31. Cevese PG, Vecchioni R, DAmico DF (1998): Postoperative chylothorax. Chest, 6:59-66.

32. Christenson J, Cohen M, Ferguson J, Freedman R, Miller M, Ohman E, Reddy R (2002): Trends in intraaortic balloon counterpulsation complications and outcomes in cardiac surgery, The Annals of thoracic surgery, 74:86-90.

33. Kolh P, Wijns W, Danchin N (2010): Guidelines on myocardial revascularization, official journal of the European Association for Cardio-thoracic Surgery, 38(S1):S1-52.

34. Ricotta JJ, Faggioli GL, Castilone A, Hassett JM (1994): Risk factors for stroke after cardiac surgery: buffalocardiac-cerebral study group. J Vasc Surg., 21(2):359-364.

35. Adelborg, Mahrholdt H, Kaski JC, SechtemU (2009): Risk factores of post coronary bypass surgery mortality. Am Heart J., 115:255-266. 